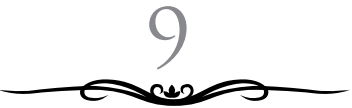

\title{
MENUJU PERPUSTAKAAN PERGURUAN TINGGI YANG BERMUTU
}

\author{
Ulya \\ STAIN Kudus, Jawa Tengah, Indonesia \\ ulya.kamera@gmail.com
}

\begin{abstract}
Indonesia's future lies on the hands of young generation. The brilliant and dynamic young generation will surely shine Indonesian's new face thorough out the world community. Higher education has a very strategic role in delivering and creating this ideal condition, particularly through the library. Information given by the collections invited the young generation to surf across the ocean of knowledge in accordance with contemporary scientific developments. Through a qualified libraries which greatly facilitate the role of universities in contributing to the intellectual life of the young generation, to advance science and technology, and apply the values of humanities in order to empower the Indonesian people on an ongoing basis. Qualified library is that which meets the quality standards set by the National Library of the Republic of Indonesia in terms of collection, building, service, library personnel, and management. This article discusses issues around qualified and standardized library mentioned above.
\end{abstract}

Key words: Library, Quality, Accreditation. 


\begin{abstract}
Abstrak
Masa depan Indonesia terletak di tangan generasi muda. Generasi muda yang brilian dan dinamis akan melahirkan wajah Indonesia bersinar di tengah masyarakat dunia. Perguruan tinggi memiliki peran yang sangat strategis dalam mengantarkan dan menciptakan kondisi ideal tersebut, terutama melalui perpustakaannya. Melalui informasi dari koleksi perpustakaan, generasi muda bisa dengan mudah diajak berselancar mengarungi samudra pengetahuan apapun sesuai dengan perkembangan keilmuan kekinian. Melalui perpustakaan yang bermutu sangat memudahkan peran perguruan tinggi dalam berkontribusi dalam mencerdaskan kehidupan generasi muda, memajukan ilmu pengetahuan dan teknologi, serta menerapkan nilai-nilai humanitis dalam rangka memberdayakan bangsa Indonesia secara berkelanjutan. Perpustakaan yang bermutu adalah perpustakan yang memenuhi standar mutu yang telah ditetapkan oleh Perpustakaan Nasional Republik Indonesia, di antaranya memenuhi standar koleksi, standar gedung, standar layanan, standar tenaga perpustakaan, dan standar manajemen. Artikel ini membahas persoalan-persoalan standar perpustakaan yang dinilai bermutu dimaksud.
\end{abstract}

Kata Kunci: Perpustakaan, Mutu, Akreditasi.

\title{
A. Pendahuluan
}

Eksistensi perpustakaan di perguruan tinggi sangat signifikan. Begitu signifikannya, perpustakaan merupakan salah satu standar dan persyaratan yang harus dipenuhi menuju perguruan tinggi bermutu. ${ }^{1}$ Ini sama artinya bahwa menuju perguruan tinggi bermutu perlu perpustakaan bermutu. Indikator bermutu dalam pendidikan tinggi ditandai dengan adanya tingkat kesesuaian antara penyelenggaraan pendidikan tinggi dengan Standar Nasional Pendidikan Tinggi dan standar

${ }^{1}$ Peraturan Menteri Riset dan Teknologi Pendidikan Tinggi atau Permenristek Dikti Nomor 44 Tahun 2015 Tentang Standar Nasional Pendidikan Tinggi Pasal 35. 
lain yang ditetapkan oleh perguruan tinggi. ${ }^{2}$ Demikian pula berkaitan dengan perpustakaan bermutu, bahwa perpustakaan bermutu pun harus ditandai dengan adanya tingkat kesesuaian antara penyelenggaraan perpustakaan sesuai dengan standar yang telah ditetapkan oleh Perpustakaan Nasional Republik Indonesia (Perpusnas RI) dan standar lain yang ditetapkan secara internal perpustakaan dimaksud ataupun oleh lainnya, seperti BAN-PT (Badan Akreditasi Nasional Perguruan Tinggi).

Adapun untuk mengukur tingkat mutu perpustakaan bisa dilakukan dengan dua cara, yaitu secara internal dan eksternal. Secara internal jika pengukuran mutu perpustakaan tersebut menjadi bagian dari kegiatan sistemik penjaminan mutu pendidikan tinggi oleh perguruan tinggi itu sendiri, dilakukan secara otonom dalam rangka untuk mengendalikan dan meningkatkan penyelenggaraan pendidikan tinggi secara keseluruhan, berencana, dan berkelanjutan. Sementara, secara eksternal jika pengukuran mutu dilakukan oleh pihak lain sebagai kegiatan penilaian melalui akreditasi untuk menentukan kelayakan dan tingkat pencapaian mutu perpustakaan tersebut. Biasanya semakin tinggi nilai akreditasi dinilai, semakin bermutu. Sebaliknya, semakin rendah nilai akreditasi dinilai, semakin tak bermutu. Istilah lainnya bahwa akreditasi merupakan bukti keterpercayaan dan kualitas penyelenggaraan sebuah lembaga: perguruan tinggi, perpustakaan, dan lain-lain.

Artikel ini secara khusus akan membicarakan persoalan yang kedua. Oleh karena itu, berikut akan dibahas secara berturutturut adalah tentang perpustakaan perguruan tinggi, standar nasional perpustakaan perguruan tinggi, dan persiapan menuju akreditasi perpustakaan perguruan tinggi.

${ }^{2}$ Kebijakan Nasional Sistem Penjaminan Mutu Pendidikan Tinggi Berdasarkan Undang-undang Nomor 12 Tahun 2012 Tentang Pendidikan Tinggi dan Permendikbud Nomor 50 Tahun 2014 Tentang Sistem Penjaminan Mutu Pendidikan Tinggi. 


\section{B. Pembahasan}

\section{Perpustakaan Perguruan Tinggi}

Dalam Kamus Besar Bahasa Indonesia (KBBI) disebutkan bahwa perpustakaan berasal dari kata dasar pustaka, yang artinya: kitab, buku, atau buku primbon. Dengan demikian, perpustakaan berarti tempat, gedung, atau ruangan yang disediakan untuk pemeliharan dan penggunaan koleksi buku, dan sebagainya; atau koleksi buku, majalah, dan bahan kepustakaan lain yang disimpan untuk dibaca, dipelajari, dan dibicarakan. ${ }^{3}$ Adapun menurut Undang-undang Republik Indonesia Nomor 43 Tahun 2007 Tentang Perpustakaan, perpustakaan adalah institusi pengelola koleksi karya tulis, karya cetak, dan/atau karya rekam secara profesional dengan sistem baku guna memenuhi kebutuhan pendidikan, penelitian, pelestarian informasi, dan rekreasi para pemustaka. ${ }^{4}$

Institusi perpustakaan yang demikian menjadi penting adanya dalam berdirinya sebuah perguruan tinggi dalam melaksanakanmisiTriDharma PerguruanTinggi,yaitu:pendidikan dan pengajaran, penelitian, dan pengabdian kepada masyarakat, dengan tujuan akhirnya adalah mencerdaskan kehidupan bangsa, memajukan serta menyebarkan ilmu pengetahuan dan teknologi dalam rangka memberdayakan bangsa Indonesia secara kontinu.

Perpustakaan wajib adanya dalam setiap perguruan tinggi. Ia menjadi salah satu syarat berdirinya perguruan tinggi. Dalam Undang-undang Nomor 20 Tahun 2003 Tentang Sistem Pendidikan Nasional pada Pasal 55 menyebutkan bahwa salah satu syarat untuk menyelenggarakan perguruan tinggi harus memiliki perpustakaan. Keberadaan perpustakaan perguruan tinggi sebagai Unit Pelaksana Teknis (UPT) yang bersama-sama dengan unit lain adalah melaksanakan Tri Dharma Perguruan

${ }^{3}$ Pusat Bahasa Departemen Pendidikan Nasional, Kamus Besar Bahasa Indonesia (Jakarta: Gramedia, 2008), hlm. 1121.

${ }^{4}$ Undang-undang Republik Indonesia Nomor 43 Tahun 2007 Tentang Perpustakaan. 
Tinggi dengan tugas khusus menghimpun, memilih, mengolah, merawat, serta melayani sumber informasi kepada lembaga induk khususnya dan masyarakat akademis pada umumnya. ${ }^{5}$

Perpustakaan yang berdiri di tengah-tengah perguruan tinggi seperti itu, baik di universitas, institut, sekolah tinggi, ataupun akademi yang secara bersama-sama mengemban misi Tri Dharma Perguruan Tinggi tersebut, secara khusus disebut dengan perpustakan perguruan tinggi. ${ }^{6}$ Lebih luas lagi yang termasuk perpustakaan perguruan tinggi adalah semua perpustakaan yang terdapat pada perguruan tinggi, juga badan bawahannya ataupun lembaga yang berafiliasi dengan perguruan tinggi, seperti: perpustakaan pada tingkat fakultas, jurusan, program studi, juga perpustakaan yang berada di bawah unit atau pusat, seperti: pusat penelitian, pusat-pusat studi, dan lain-lain.

Jika secara umum perpustakaan di perguruan tinggi bertugas dan bertujuan memperlancar misi dan tugas perguruan tinggi dalam melaksanakan Tri Dharma Perguruan Tinggi tersebut, maka secara mendetail perpustakaan perguruan tinggi bertujuan untuk:

a. Memenuhi keperluan informasi masyarakat perguruan tinggi, lazimnya pengajar dan mahasiswa;

b. Menyediakan bahan pustaka rujukan (referensi) pada semua tingkat akademik, artinya mulai dari mahasiswa tahun pertama hingga mahasiswa pascasarjana dan pengajarnya;

c. Menyediakan ruang belajar untuk pemakai perpustakaan;

d. Menyediakan jasa peminjaman yang tepat guna bagi

${ }^{5}$ Undang-undang Nomor 20 Tahun 2003 Tentang Sistem Pendidikan Nasional Pasal 55.

${ }^{6}$ Wirawan, Evaluasi, Teori, Model, Standar, Aplikasi, dan Profesi: Contoh Aplikasi Evaluasi Program Pengembangan Sumber Daya Manusia, Program Nasional Pemberdayaan Masyarakat (PNPM) Mandiri Pedesaan, Kurikulum, Perpustakaan, dan Buku Teks (Jakarta: Raja Grafindo Persada, 2012), hlm. 249. 
berbagai jenis pemakai;

e. Menyediakan jasa informasi aktif yang tidak saja terbatas pada lingkungan perguruan tinggi tetapi juga lembaga industri lokal. ${ }^{7}$

Selanjutnya hal-hal yang harus diperhatikan dalam penyelenggaraan perpustakaan di perguruan tinggi adalah:

a. Setiap perguruan tinggi menyelenggarakan perpustakaan yang memenuhi standar nasional perpustakaan dengan memperhatikan Standar Nasional Pendidikan;

b. Perpustakaan sebagaimana dimaksud memiliki koleksi, baik jumlah judul maupun jumlah eksemplarnya, yang mencukupi untuk mendukung pelaksanaan pendidikan, penelitian, dan pengabdian kepada masyarakat;

c. Perpustakaan perguruan tinggi mengembangkan layanan perpustakaan berbasis teknologi informasi dan komunikasi;

d. Setiap perguruan tinggi mengalokasikan dana untuk pengembangan perpustakaan sesuai dengan peraturan perundang-undangan guna memenuhi standar nasional pendidikan dan standar nasional perpustakaan. ${ }^{8}$

\section{Standar Nasional Perpustakaan Perguruan Tinggi}

Sebagaimana telah disampaikan di depan bahwa perpustakaan bermutu jika sebuah perpustakaan diselenggarakan dan dikelola sesuai dengan standar yang telah ditetapkan. Adapun standar nasional perpustakaan tersebut, idealnya, disusun dan ditetapkan oleh kesepakatan antara para pakar kepustakawanan dan profesi kepustakawanan serta diterima oleh para pustakawan pada umumnya. ${ }^{9}$ Standar tersebut meliputi ukuran kualitas dan

7 Sulistyo Basuki, Pengantar Ilmu Perpustakaan (Jakarta: Gramedia Pustaka Utama, 1991), hlm. 52.

8 Undang-Undang Nomor 43 Tahun 2007 Tentang Perpustakaan Pasal 24.

${ }^{9}$ Wirawan, Evaluasi, Teori, Model, Standar, Aplikasi, dan Profesi, hlm. 250. Tentang pustakawan sendiri adalah tenaga kerja bidang perpustakaan yang telah memiliki ilmu manajemen perpustakaan, baik melalui pendidikan, 
kuantitas batas bawah dari semua aspek yang berkaitan dengan perpustakaan. Konkretnya di Indonesia bahwa standar minimal nasional yang harus melekat dalam sebuah perpustakaan perguruan tinggi di tetapkan oleh tim dari Perpustakaan Nasional RI. ${ }^{10}$

Adapun secara umum isi standar tersebut mengatur antara lain: ${ }^{11}$

a. Standar koleksi

Perpustakaan dapat menyajikan layanan untuk melaksanakan fungsinya jika mempunyai koleksi bahan pustaka yang mencukupi. Menurut medianya, koleksi bahan pustaka tersebut antara lain berupa: koleksi buku, koleksi langka, koleksi penerbitan berkala, seperti: surat kabar, jurnal ilmiah, majalah; koleksi peta; koleksi media teknologi, seperti: film, microfilm, slide, dan compact disc; koleksi paten; koleksi tesis dan disertasi; koleksi database, berupa: koleksi artikel surat kabar, majalah, jurnal ilmiah dalam bentuk digital yang dapat diakses dengan standalone atau online dengan komputer.

b. Standar gedung

Agar dapat menyajikan layanan dengan baik dan nyaman, perpustakaan memerlukan gedung yang standar, yang di dalamnya memuat ruangan-ruangan yang diperlukan untuk pelayanan dan penyimpanan koleksi. Standardisasi gedung perpustakaan antara lain terdiri atas berbagai jenis ruangan, luas ruangan dengan ukuran tertentu, kualitas ruangan, dan seterusnya. Standar gedung

kursus, seminar, maupun kegiatan sekolah formal. Ia bertanggung jawab terhadap gerak maju roda perpustakaan. Dalam lingkungan PNS, pustakawan termasuk ke dalam jabatan fungsional. Kerja pustakawan sekarang ini tidak hanya sebagai pemelihara bahan pustaka dan sumber informasi lainnya, tetapi dia juga harus aktif menjadi sumber dan menyajikan informasi. Wiji Suwarno, Perpustakaan dan Buku: Wacana, Penulisan, dan Penerbitan (Yogyakarta: arRuzz Media, 2011), hlm. 37.

${ }^{10}$ Wirawan, Evaluasi, Teori, Model, Standar, Aplikasi, dan Profesi, hlm. 251.

${ }^{11}$ Ibid., hlm. 252-255. Uraian di atas merupakan ringkasan dari karya Wirawan sebagaimana dalam kutipan, kecuali bagian-bagian tertentu yang disebutkan sumber lainnya. 
berbeda, tergantung jenis dan jumlah koleksi, jenis pemustaka, dan jenis layanannya.

c. Standar tenaga perpustakaan

Layanan perpustakaan, pemeliharaan, dan pengembangannya dilaksanakan oleh tenaga profesioanal pustakawan yang memenuhi standar tenaga pustakawan dalam pengertian kualitas, jumlah, dan struktur jenisnya. Standar tenaga pustakawan harus memenuhi juga jumlah dan struktur sosial masyarakat yang dilayani. Misalnya: perpustakaan umum di kota kecil jumlah dan kualitas tenaga pustakawannya berbeda dengan perpustakaan di kota besar. Demikian juga perpustakaan di perguruan tinggi.

Dari kriteria profesionalisme, tenaga pustakawan dapat dikelompokkan menjadi beberapa kelompok, yaitu: ada tenaga profesional pustakawan yang minimal berpendidikan sarjana; ada profesional pustakawan spesialis bidang konservasi dan reproduksi bahan pustaka; profesional spesialis information technology, profesional spesialis sarana dan prasarana perpustakaan; profesional spesialis bidang ilmu tertentu; profesional spesialis manajemen umum, keuangan, dan library marketing; para profesional pustakawan bidang perpustakaan berpendidikan diploma; dan teknisi perpustakaan, dan lain-lain.

d. Standar teknis perpustakaan

Koleksi perpustakaan harus disusun secra sistematis menurut standar teknis ilmu perpustakaan agar mudah ditempatkan dan ditemukan di rak penyimpanan. Koleksi harus diklasifikasikan menurut sistem klasifikasi tertentu, seperti: Dewey Decimal Calssification, Universal Decimal Classification, atau Library of Conggres Classification System. Setiap butir koleksi perpustakaan juga dibuatkan dokumen sekundernya, katalog, indeks, atau abstrak, dibuatkan nomor panggil atau call number agar mudah ditelusur dan ditemukan kembali dengan tepat dan cepat.

e. Standar layanan

Perpustakaan adalah institusi layanan publik. Fungsi setiap perpustakaan dijabarkan dan dilaksanakan melalui layanan 
perpustakaan. Setiap layanan disusun secara sistematis dalam pengertian mempunyai tujuan dan manfaat yang akan dicapai, dan standar proses setiap layanan. Dengan demikian, pemustaka akan mendapatkan layanan informasi yang prima, tepat, dan cepat.

f. Standar manajemen perpustakaan

Dalam penyelenggaraan manajemen perpustakaan, minimal ada empat bagian atau unsur, yaitu kepala perpustakaan, unit tata usaha, unit pelayanan teknis, dan unit pelayanan pembaca. Kepala perpustakaan bertugas menggerakkan setiap tenaga dan mengerahkan segala fasilitas kerja agar perpustakaan dapat terselenggara dengan sebaik-baiknya sesuai dengan tujuannya. Sementara, unit tata usaha memiliki tugas khusus yang berkaitan dengan masalah surat menyurat, personalia, keuangan, pengadaan, dan pemeliharaan sarana prasarana perpustakaan. Adapun tugas unit pelayanan teknis adalah memproses atau mengolah bahanbahan pustaka secara sistematis sesuai dengan aturan yang berlaku. Kegiatan unit ini antara lain berupa pengadaan bahan pustaka, inventarisasi, klasifikasi, katalogisasi, membuat perlengkapanperlengkapan buku, seperti: label buku atau call number, kantong buku, slip tanggal, dan menyusun buku-buku yang telah diproses di almari dan rak yang sudah tersedia. Adapun tugas pelayanan pembaca adalah melayani peminjaman dan pengembalian bukubuku, memberikan bimbingan membaca atau memberikan bantuan informasi kepada yang memerlukan. ${ }^{12}$

Selanjutnya, standar manajemen perpustakaan yang mengatur pelaksanaan berbagai fungsi manajemen perpustakaan, antara lain terdiri atas:

a. Struktur organisasi internal perpustakaan (unit-unit kerja perpustakaan dan ekselonisasinya) dan struktur organisasi eksternal perpustakaan dalam kaitannya dengan organisasi induknya (posisi eselon perpustakaan dalam kaitan eselon organisasi induknya);

12 Andi Prastowo, Manajemen Perpustakaan Sekolah Profesional (Yogyakarta: Diva Press, 2012), hlm. 94-95. 
b. Pelaksanaan fungsi-fungsi manajemen perpustakaan dan unit-unitnya (planning, organizing, actuating/leading, and controlling);

c. Standar anggaran perpustakaan. Perpustakaan memerlukan anggaran khusus untuk pengadaan bahan pustaka, gaji tenaga perpustakaan, gaji tenaga perpustakaan, biaya penyelenggaraan layanan, dan biaya operasional perpustakaan lainnya;

d. Budaya organisasi perpustakaan, yang terdiri atas visi, misi, dan nilai-nilai strategis perpustakaan.

\section{Persiapan Menuju Akreditasi Perpustakaan Perguruan Tinggi}

Berangkat dari penjelasan di depan, maka sesungguhnya untuk setiap perpustakaan, termasuk perpustakaan perguruan tinggi, minimal harus memenuhi beragam standar di atas, yaitu ada standar koleksi, standar layanan, standargedung dan ruang, standar manajemen, dan lain-lain. Selanjutnya, menuju perpustakaan yang semakin berkualitas dan berkelas seharusnya tidak hanya berhenti pada standar nasional tersebut, tetapi harus bisa melampauinya. Dengan melampaui standar minimal perpustakaan, maka penyelenggaraan perpustakaan dapat dinyatakan semakin bermutu. Pengakuan keterpercayaan atau pengakuan bermutu tidaknya sebuah perpustakaan, di antaranya akreditasi menjadi sebuah kegiatan yang sering kali dipertaruhkan.

Membicarakan tentang akreditasi, termasuk akreditasi perpustakaan, adalah memperbincangkan tentang persoalan proses, hasil, juga sebuah kondisi. Sebagai proses, maka akreditasi merupakan suatu upaya pihak luar, untuk menilai dan menentukan status kualitas sebuah institusi, termasuk perpustakaan, berdasarkan standar mutu yang telah ditetapkan. Sebagai hasil, maka akreditasi merupakan status mutu institusi yang diumumkan kepada masyarakat. Adapun sebuah kondisi, artinya jika sebuah institusi sudah terakreditasi, maka hal itu akan memberikan kepercayaan kepada publik bahwa sebuah perpustakaan beserta koleksi, layanan jasa, sumber daya manusia, 
dan sarana-prasarana lainnya telah memenuhi komitmen pada mutu perpustakaan. Adanya kondisi sebuah perpustakaan yang terakreditasiakan memberikan jaminan bahwa institusi tersebut telah memenuhi standar mutu yang ditetapkan sehingga mampu memberikan perlindungan bagi masyarakat dari penyelenggaraan perpustakaan yang tidak memenuhi standar.

Adapun secara khusus yang disebut dengan akreditasi perpustakaan adalah rangkaian kegiatan proses pengakuan formal oleh LAP-N yang menyatakan bahwa suatu lembaga perpustakaan telah memenuhi standar untuk melakukan kegiatan pengelolaan perpustakaan. ${ }^{13}$ LAP-N adalah Lembaga Akreditasi Perpustakaan Nasional. LAP-N ini merupakan unit penyelenggara akreditasi yang sudah mendapatkan pengakuan tertulis atau sertifikat dari Perpusnas RI untuk menyelenggarakan akreditasi di semua jenis perpustakaan yang ada di Indonesia, termasuk perpustakaan perguruan tinggi. ${ }^{14}$

Dalam perjalanan sejarah di Indonesia, akreditasi perpustakaan perguruan tinggi tidak hanya dilakukan oleh LAP-N tersebut, tetapi juga dilakukan oleh BAN-PT tatkala BANPT sedang melakukan akreditasi program studi atau institusi perguruan tinggi yang bersangkutan. Perpustakaan merupakan salah satu komponen yang dinilai dalam proses akreditasi program studi atau institusi tersebut. Jadi dalam praktiknya, pelaksana akreditasi perpustakaan perguruan tinggi ada dua, yaitu LAP-N dan BAN-PT. Adapun dalam pembahasan artikel ini mengkhususkan pada kajian dan kelengkapannya yang dilakukan oleh pihak pertama, yaitu: LAP-N, bukan BAN-PT.

Selanjutnya tentang hal-hal yang dinilai dalam proses akreditasi ada bermacam-macam. Dari standar minimal umum nasional perpustakaan perguruan tinggi sebagaimana telah dijelaskan dalam sub bahasan di atas, maka diturunkan

${ }^{13}$ Perpustakaan Nasional Republik Indonesia (Perpusnas RI), Pedoman Pembentukan Lembaga Akreditasi Perpustakaan Provinsi (Jakarta : Perpusnas RI, 2014), hlm. 2.

${ }^{14}$ Ibid. 
menjadi rincian komponen-komponen sekaligus indikatorindikator yang harus diperhatikan dalam penyiapan akreditasi perpustakaan, yaitu: ${ }^{15}$

a. Komponen koleksi

Koleksi merupakan jantung perpustakaan. Tanpa koleksi, perpustakaan tersebut hanya berupa gedung yang mati. Adapun hal-hal yang harus dipersiapkan dalam menghadapi akreditasi berkenaan dengan koleksi adalah tentang jumlah koleksi secara keseluruhanyangberupakaryacetak; berapa persentasekeberadaan koleksi inti, yakni koleksi yang berhubungan langsung dengan kurikulum, jika dibandingkan dengan koleksi perpustakaan secara keseluruhan; jenis buku referensi, macam surat kabar yang dilanggan, juga jurnal ilmiah yang dilanggan; ada atau tidaknya koleksi khusus, seperti: skripsi, tesis, disertasi, hasil penelitian; lalu tentang seberapa banyak penambahan koleksi per tahun; yang berkaitan dengan stock opname; dan survey kebutuhan koleksi.

b. Komponen gedung, ruangan, dan sarana-prasarana

Gedung dan lain-lain adalah bentuk konkret dari perpustakaan. Banyak hal yang harus diperhatikan dan dipenuhi dalam persoalan ini, yakni:

1) Berkaitan dengan luas gedung dan macam ruangan

Dalam persoalan ini bahwa area koleksi harus memenuhi 45\% dari keseluruhan luas gedung, dan area ini akan meliputi ruang bahan rujukan, ruang buku teks, ruang jurnal, ruang koleksi multimedia, ruang surat kabar dan kliping; lalu area pemustaka yang seharusnya memenuhi 25\% dari luas keseluruhan gedung, yakni untuk ruang sirkulasi, ruang katalog, tempat display koleksi baru, ruang pertemuan, ruang baca, ruang penitipan barang; lalu area staf yang idealnya harus memenuhi 20\% dari keseluruhan luas gedung, meliputi: ruang pimpinan, tata usaha, ruang pengolahan, ruang

${ }^{15}$ Perpustakaan Nasional Republik Indonesia, Akreditasi Perpustakaan Perguruan Tinggi (Jakarta: Perpusnas RI, 2013), hlm. 2-26. 
makan; dan area lain $10 \%$, yaitu untuk lobi, ruang tamu, dan toilet.

2) Yang juga harus dicermati dalam komponen ini adalah yang berkaitan dengan kebersihan ruangan atau area, penerangan, sirkulasi udara, dan keamanan.

3) Selain itu, juga tentang ada tidaknya dan mencukupi tidak mencukupinya rak surat kabar, rak buku, rak referensi, rak jurnal, rak multimedia, rak display buku baru, loker, filing cabinet, papan pengumuman, meja baca individu dan kelompok, meja sirkulasi, meja kerja petugas, kursi baca, komputer dan printer untuk petugas ataupun pemustaka, scanner, perangkat multimedia, televisi, AC, dan kipas angin.

c. Komponen sumber daya manusia atau tenaga perpustakaan

Akreditasi juga memfokuskan perhatiannya pada yang berkaitan dengan sumber daya manusia, yakni orang-orang atau pihak-pihak yang terlibat dalam penyelenggaraan perpustakaan. Adapun yang menjadi pokok penilaian adalah status dan kelengkapan minimal pengelola perpustakaan, yakni harus ada kepala perpustakaan, pustakawan, tenaga teknis, tenaga fungsional lain, juga ada-tidaknya tenaga honorarium; lalu bagaimana jenjang pendidikan formal mereka: doktor, magister, sarjana, diploma, berbasis pendidikan perpustakaan atau tidak, atau bahkan berlatar belakang SLTA; lalu pendidikan dan latihan yang pernah diikuti; kegiatan pengembangan karier mereka sebagai tenaga perpustakaan, seperti: mengikuti seminar, workshop, partisipasi dalam lomba-lomba, dan macam kegiatan pelatihan lainnya.

d. Komponen layanan

Perpustakaan menjadi salah satu institusi layanan publik, maka dalam proses akreditasi juga menyentuh persoalan ini. Berkaitan dengan layanan maka yang harus diperhatikan adalah tentang jam buka perpustakan per hari atau per minggu; 
sistem peminjaman buku menggunakan manual atau otomasi; persentase mahasiswa yang menjadi anggota perpustakaan jika dibandingkan dengan keseluruhan jumlah mahasiswa yang ada; persentase dosen dan tenaga kependidikan lain yang menjadi anggota perpustakaan jika dibndingkan dengan jumlah dosen dan tenaga kependidikan secara keseluruhan; frekwensi ratarata anggota meminjam buku dalam sebulan; jenis promosi yang pernah dilakukan: melalui sebaran brosur, mengadakan pameran atau lomba-lomba, menginformasikan koleksi baru, dan lainlain; dan frekwensi promosi dalam setahun; pelayanan berbasis teknologi dan komunikasi, serta literasi informasi. Yang berkaitan dengan layanan ini pula adalah tentang sumber daya elektronik (SDE), yakni berkenaan dengan monograf, homepage/website perpustakaan, sistem otomasi perpustakaan, dan langganan jurnal elektronik.

e. Komponen kerja sama

Komponen kerja sama juga memiliki poin tersendiri dalam proses akreditasi. Oleh karena itu, juga harus dipersiapkan dengan sebaik-baiknya. Adapun yang berkaitan dengan kerja sama perpustakaan, meliputi: kerja sama dengan perpustakaan atau institusi lain dalam rangka pengembangan perpustakaan dan kerja sama dengan perpustakaan lain dalam rangka meluaskan jangkauan layanan atau peminjaman.

\section{f. Komponen anggaran}

Anggaran menjadi faktor yang vital bagi tumbuh kembangnya sebuah perpustakaan, maka sektor anggaran juga menjadi urgen dalam penyelenggaraan perpustakaan. Dalam konteks proses akreditasi yang akan dinilai berkaitan dengan anggaran adalah meliputi sumber dan jumah anggaran; alokasi anggaran untuk perpustakaan di antara anggaran perguruan tinggi yang bersangkutan secara keseluruhan, dan pemanfaatan dana atau anggaran tersebut.

g. Komponen perawatan bahan

Kegiatan yang diperhatikan dalam komponen ini meliputi: perawatan dan penyiangan berbagai koleksi perpustakaan; 
bagaimana kegiatan itu dilaksanakan dalam arti dilakukan secara periodik atau tidak.

h. Komponen organisasi materi perpustakaan

Yang harus dicermati meliputi penggunaan alat seleksi bahan perpustakaan, pengolahan buku/monograf, pengolahan majalah baru, sistem temu kembali informasi, dan kelengkapan identitas koleksi.

i. Komponen manajemen perpustakaan

Membicarakan komponen manajemen perpustakaan, maka yang harus disiapkan dalam rangka akreditasi adalah sisi kelembagaan perpustakaan, line of command kepala perpustakaan, program kerja perpustakaan, dan penyusunan program kerja.

Sesungguhnya komponen dan indikator penilaian akreditasi di atas disusun berdasarkan pada peraturan atau pedoman yang dibuat oleh Perpustakaan Nasional RI. Selanjunya dalam rangka introspeksi awal dan mengevaluasi diri jika sebuah perpustakaan perguruan tinggi akan melakukan akreditasi, maka hal-hal tersebut di atas perlu diperhatikan. Berikut tabel yang akan menjelaskan sistem bobot nilai capaiannya dari masing-masing komponen di atas.

Komponen dan Indikator Kunci Akreditasi Perpustakaan Perguruan Tinggi

\begin{tabular}{clcc}
\hline No. & \multicolumn{1}{c}{ Komponen } & Jumlah Indikator Kunci & Bobot \\
\hline 1 & Layanan & 12 & 20 \\
\hline 2 & Kerja sama & 2 & 5 \\
\hline 3 & Koleksi & 12 & 15 \\
\hline 4 & $\begin{array}{l}\text { Pengorganisasian bahan } \\
\text { perpustakaan }\end{array}$ & 3 & 10 \\
\hline 5 & Sumber daya manusia & 10 & 15 \\
\hline 6 & Gedung/ruang, sarana prasarana & 33 & 10 \\
\hline 7 & Anggaran & 3 & 10 \\
\hline 8 & Manajemen perpustakaan & 4 & 10 \\
\hline 9 & Perawatan koleksi perpustakaan & 3 & 5 \\
\hline & $\quad$ Jumlah & 82 & $100 \%$ \\
\hline
\end{tabular}

Sumber: Instrumen Akreditasi Perpustakaan Perguruan Tinggi, 2015. 
Adapun rentang penilaian predikat akreditasi berdasarkan perolehan capaian nilai dari berbagai indikator dari masingmasing komponen di atas adalah sebagai berikut.

\begin{tabular}{cccc}
\hline No. & Nilai & Predikat & Keterangan \\
\hline 1 & $91=100$ & Akreditasi A & Amat Baik \\
\hline 2 & $76-90$ & Akreditasi B & Baik \\
\hline 3 & $60-75$ & Akreditasi C & Cukup Baik \\
\hline 4 & $<60$ & Belum terakreditasi & $\begin{array}{c}\text { Nilai 60 adalah batas minimal } \\
\text { kelulusan, merupakan akumulasi } \\
\text { dari rata-rata semua unsur }\end{array}$ \\
\hline
\end{tabular}

\section{Simpulan}

Berangkat dari keseluruhan pembahasan di atas, maka beberapa hal yang perlu digarisbawahi berkenaan dengan tulisan di atas bahwa sesungguhnya perpustakaan perguruan tinggi merupakan salah satu unit layanan publik, yang khususnya melayani civitas akademika perguruan tinggi yang bersangkutan, dalam rangka mengimplementasikan misi Tri Dharma Perguruan Tinggi, yaitu pendidikan dan pengajaran, peneitian, dan pengabdian kepada masyarakat.

Bermutu tidaknya sebuah layanan perpustakaan perguruan tinggi tersebut sangat tergantung pada puas tidaknya stakeholder, dalam hal ini adalah pemustaka, mendapatkan pelayanan dari penyelenggaraan perpustakaan tersebut. Untuk mengukur prima tidaknya pelayanan dari penyelenggaraan perpustakaan bisa diukur dari kaca mata terpenuhinya standar-standar yang telah ditetapkan oleh yang berwenang, yaitu pihak Perpustakaan Nasional Republik Indonesia.

Untuk menilai sesuai tidaknya standar penyelenggaraan perpustakaan dimaksud, maka kegiatan akreditasi niscaya harus dilakukan. Nantinya, semakin tinggi nilai capaian akreditasi, maka perpustakaan tersebut dinilai semakin bermutu, sehat dalam penyelennggaraannya, baik melakukan layanannya, lengkap koleksinya, dan lain-lain sehingga semakin meningkat ketepercayaan publik terhadapnya. 


\section{DAFTAR PUSTAKA}

Basuki, Sulistyo. Pengantar Ilmu Perpustakaan. Jakarta: Gramedia Pustaka Utama, 1991.

Kebijakan Nasional Sistem Penjaminan Mutu Pendidikan Tinggi Berdasarkan Undang-undang Nomor 12 Tahun 2012 Tentang Pendidikan Tinggi.

Peraturan Menteri Pendidikan dan Kebudayaan Nomor 50 Tahun 2014 Tentang Sistem Penjaminan Mutu Pendidikan Tinggi.

Peraturan Menteri Riset dan Teknologi Pendidikan TinggiNomor 44 Tahun 2015 Tentang Standar Nasional Pendidikan Tinggi. Perpustakaan Nasional Republik Indonesia. Akreditasi Perpustakaan Perguruan Tinggi. Jakarta: Perpusnas RI, 2013. . Pedoman Pembentukan Lembaga Akreditasi Perpustakaan Provinsi. Jakarta: Perpusnas RI, 2014.

Prastowo, Andi. Manajemen Perpustakaan Sekolah Profesional. Yogyakarta: Diva Press, 2012.

Pusat Bahasa Departemen Pendidikan Nasional. Kamus Besar Bahasa Indonesia. Jakarta: Gramedia, 2008.

Suwarno, Wiji. Perpustakaan dan Buku: Wacana, Penulisan, dan Penerbitan. Yogyakarta: ar-Ruzz Media, 2011.

Undang-undang Nomor 20 Tahun 2003 Tentang Sistem Pendidikan Nasional.

Undang-undang Republik Indonesia Nomor 43 Tahun 2007 Tentang Perpustakaan.

Wirawan. Evaluasi, Teori, Model, Standar, Aplikasi, dan Profesi: Contoh Aplikasi Evaluasi Program Pengembangan Sumber Daya Manusia, Program Nasional PEmberdayaan Masyarakat (PNPM) Mandiri Pedesaan, Kurikulum, Perpustakaan, dan Buku Teks. Jakarta: Raja Grafindo Persada, 2012. 
Halaman ini bukan sengaja untuk dikosongkan 